\title{
THE
}

$5-4-2015$

\section{Glacial-Interglacial Changes in Central Tropical Pacific Surface Seawater Property Gradients}

\author{
Jean Lynch-Stieglitz \\ Pratigya J. Polissar \\ Allison W. Jacobel \\ Steven A. Hovan \\ Robert A. Pockalny \\ University of Rhode Island, robp@gso.uri.edu
}

See next page for additional authors

Follow this and additional works at: https://digitalcommons.uri.edu/gsofacpubs

Terms of Use

All rights reserved under copyright.

\section{Citation/Publisher Attribution \\ Jean Lynch-Stieglitz, Pratigya J. Polissar, Allison W. Jacobel, Steven A. Hovan, Robert A. Pockalny, Mitchell Lyle, Richard W. Murray, A. Christina Ravelo, Samantha C. Bova, Ann G. Dunlea, Heather L. Ford, Jennifer E. Hertzberg, Christina A. Wertman, Ashley E. Maloney, Julia K. Shackford, Katherine Wejnert and Ruifang C. Xie. (2015). "Glacial-Interglacial Changes in Central Tropical Pacific Surface Seawater Property Gradients." Paleoceanography, 30(5), 423-438.}

Available at: https://doi.org/10.1002/2014PA002746

This Article is brought to you for free and open access by the Graduate School of Oceanography at DigitalCommons@URI. It has been accepted for inclusion in Graduate School of Oceanography Faculty Publications by an authorized administrator of DigitalCommons@URI. For more information, please contact digitalcommons-group@uri.edu. 


\section{Authors}

Jean Lynch-Stieglitz, Pratigya J. Polissar, Allison W. Jacobel, Steven A. Hovan, Robert A. Pockalny, Mitchell Lyle, Richard W. Murray, A. Christina Ravelo, Samantha C. Bova, Ann G. Dunlea, Heather L. Ford, Jennifer E. Hertzberg, Christina A. Wertman, Ashley E. Maloney, Julia K. Shackford, Katherine Wejnert, and Ruifang C. Xie 


\section{Paleoceanography}

\section{RESEARCH ARTICLE \\ 10.1002/2014PA002746 \\ Glacial-interglacial changes in central tropical Pacific surface seawater property gradients}

Key Points:

- Central tropical Pacific sediment cores for paleoceanographic study collected

- Preliminary stratigraphy established for Line Islands Ridge sediment cores

- Enhanced G. ruber oxygen isotope gradient during glacials

Supporting Information:

- Figure S1 and Tables S1 and S2

Correspondence to:

J. Lynch-Stieglitz,

jean@eas.gatech.edu

\section{Citation:}

Lynch-Stieglitz, J., et al. (2015), Glacialinterglacial changes in central tropical Pacific surface seawater property gradients, Paleoceanography, 30, 423-438, doi:10.1002/2014PA002746.

Received 27 OCT 2014 Accepted 18 MAR 2015 Accepted article online 23 MAR 2015 Published online 4 MAY 2015

\author{
Jean Lynch-Stieglitz ${ }^{1}$, Pratigya J. Polissar ${ }^{2}$, Allison W. Jacobel ${ }^{2}$, Steven A. Hovan ${ }^{3}$, Robert A. Pockalny ${ }^{4}$, \\ Mitchell Lyle ${ }^{5}$, Richard W. Murray ${ }^{6}$, A. Christina Ravelo ${ }^{7}$, Samantha C. Bova ${ }^{8}$, Ann G. Dunlea ${ }^{6}$, \\ Heather L. Ford ${ }^{7}$, Jennifer E. Hertzberg ${ }^{9}$, Christina A. Wertman ${ }^{4}$, Ashley E. Maloney ${ }^{10}$, \\ Julia K. Shackford ${ }^{9}$, Katherine Wejnert ${ }^{1}$, and Ruifang C. Xie ${ }^{11}$

\begin{abstract}
${ }^{1}$ School of Earth and Atmospheric Sciences, Georgia Institute of Technology, Atlanta, Georgia, USA, ${ }^{2}$ Lamont-Doherty Earth Observatory, Columbia University, Palisades, New York, USA, ${ }^{3}$ Geoscience Department, Indiana University of Pennsylvania, Indiana, Pennsylvania, USA, ${ }^{4}$ Graduate School of Oceanography, University of Rhode Island, Narragansett, Rhode Island, USA, ${ }^{5}$ College of Earth, Ocean and Atmospheric Sciences, Oregon State University, Corvallis, Oregon, USA, ${ }^{6}$ Department of Earth and Environment, Boston University, Boston, Massachusetts, USA, ${ }^{7}$ Ocean Sciences Department, University of California, Santa Cruz, California, USA, ${ }^{8}$ Department of Earth, Environmental and Planetary Sciences, Brown University, Providence, Rhode Island, USA, ${ }^{9}$ Department of Oceanography, Texas A\&M University, College Station, Texas, USA, ${ }^{10}$ School of Oceanography, University of Washington, Seattle, Washington, USA, ${ }^{11}$ Department of Biogeochemistry, Max-Planck-Institut für Chemie, Mainz, Germany
\end{abstract}

Abstract Much uncertainty exists about the state of the oceanic and atmospheric circulation in the tropical Pacific over the last glacial cycle. Studies have been hampered by the fact that sediment cores suitable for study were concentrated in the western and eastern parts of the tropical Pacific, with little information from the central tropical Pacific. Here we present information from a suite of sediment cores collected from the Line Islands Ridge in the central tropical Pacific, which show sedimentation rates and stratigraphies suitable for paleoceanographic investigations. Based on the radiocarbon and oxygen isotope measurements on the planktonic foraminifera Globigerinoides ruber, we construct preliminary age models for selected cores and show that the gradient in the oxygen isotope ratio of $G$. ruber between the equator and $8^{\circ} \mathrm{N}$ is enhanced during glacial stages relative to interglacial stages. This stronger gradient could reflect enhanced equatorial cooling (perhaps reflecting a stronger Walker circulation) or an enhanced salinity gradient (perhaps reflecting increased rainfall in the central tropical Pacific).

\section{Introduction}

It has been demonstrated that the tropical Pacific ocean-atmosphere system exerts a critical control on global climate on timescales from interannual (El Niño-Southern Oscillation) to decadal and longer. Despite the progress in understanding this system on interannual to decadal time scales, we still have a limited understanding of how the ocean-atmosphere dynamics in the tropical Pacific changed over the last glacial cycle. Theoretical and modeling work suggests a number of potentially competing mechanisms for tropical climate change. Decreases in the amount of tropospheric water vapor due to cooler temperatures during glacial times would, all else being equal, lead to a strengthening of convective mass flux and a stronger Walker circulation and stronger equatorial upwelling [Held and Soden, 2006]. DiNezio et al. [2011] analyze the Paleoclimate Model Intercomparison Project's Last Glacial Maximum (LGM) simulations and assess the degree to which they follow these expectations. While they find an overall increase in the strength of the atmospheric circulation in the tropics for all models, the LGM tropical Pacific atmospheric circulation in each model is different and reflects a complex interplay between various factors. These factors include not only the tendency of decreased water vapor in the cooler atmosphere to increase circulation but also the tendency of the Northern Hemisphere ice sheets to shift atmospheric circulation patterns to the south, as well as the emergence of an Indonesian Maritime Continent that shifts convection to the Indian Ocean.

The data from sediment cores also present a complex picture. The Walker circulation has been interpreted as having strengthened [Feldberg and Mix, 2002; Lea et al., 2000; Martinez et al., 2003; Mix et al., 1999] and diminished [Koutavas et al., 2002; Koutavas and Lynch-Stieglitz, 2003; Sadekov et al., 2013] based on reconstructed sea surface temperatures. However, models do not show a clear link between the east-west sea surface temperature gradient and the strength of the Walker circulation [DiNezio et al., 2011], and the interpretation of 

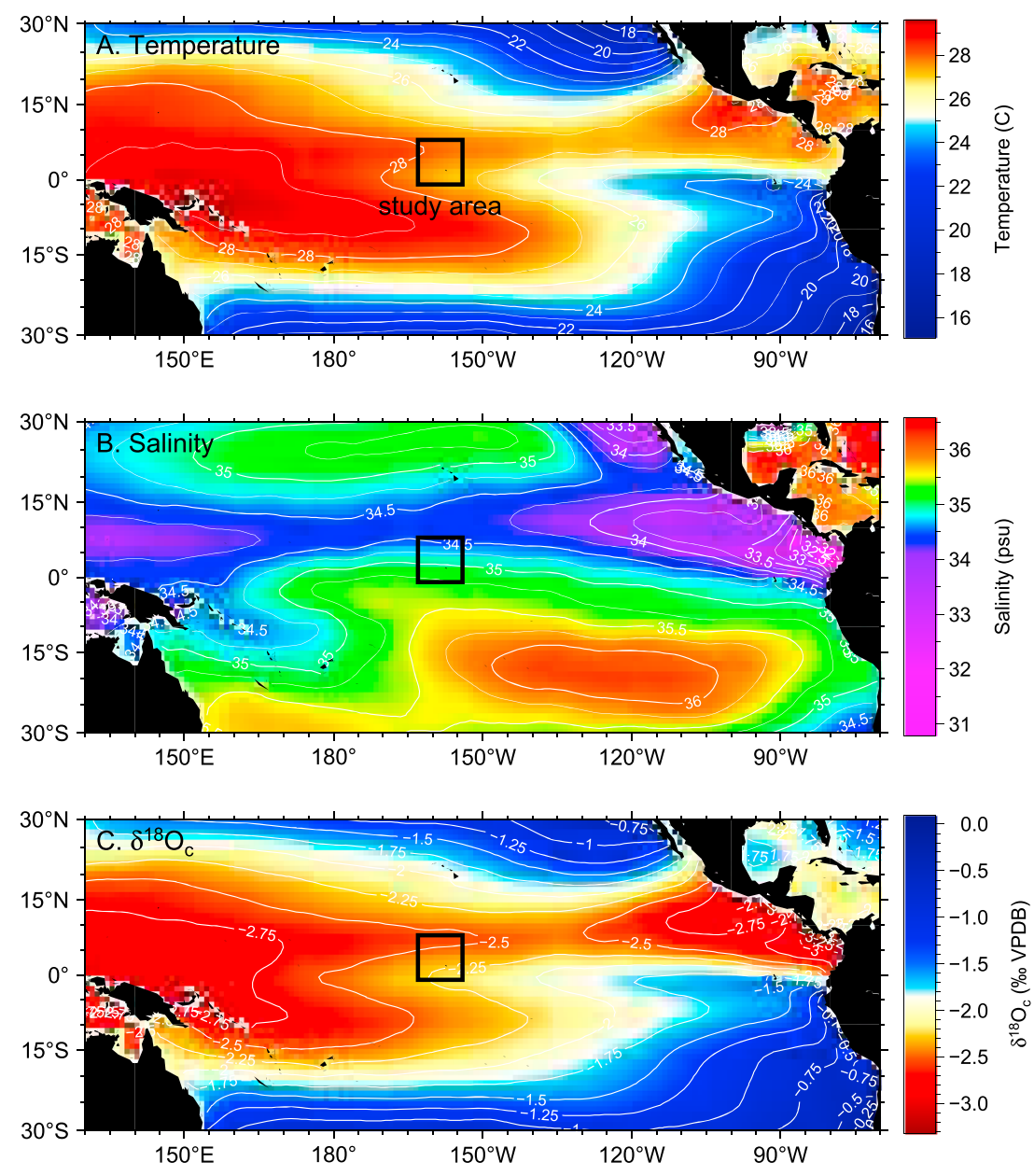

Figure 1. Mean annual (a) sea surface temperature and (b) sea surface salinity in the tropical Pacific from the World Ocean Atlas 2013 [Locarnini et al., 2013; Zweng et al., 2013]. The predicted (c) $\delta^{18} \mathrm{O}$ of calcite is computed from the tropical Pacific salinity- $\delta{ }^{18} \mathrm{O}_{\text {water }}$ relationship [LeGrande and Schmidt, 2006] and the temperature-dependent calcite-water fractionation factor of Kim and O'Neil [1997]. The Line Islands study area in Figure 2 is indicated with the black box.

different proxies for surface temperature records is complicated by the strong seasonality in the eastern tropical Pacific [e.g., de Garidel-Thoron et al., 2007; Feldberg and Mix, 2002; Steinke et al., 2008]. Investigations of changes in freshwater fluxes from proxies of surface water isotopic composition suggest a decrease in the seawater $\delta^{18} \mathrm{O}$ (and presumably salinity) gradient across the equator in the eastern tropical Pacific during the LGM [Dubois et al., 2009; Pahnke et al., 2007]. These studies interpret the reduced gradient as a consequence of a southward shift of the Intertropical Convergence Zone (ITCZ). The suggestion of enhanced convection in the Southern Hemisphere finds support in a thermocline depth reconstruction from the western tropical Pacific [Leech et al., 2013].

Many of the well-resolved paleoceanographic records from the tropical Pacific covering the last glacial cycle come from the eastern and western sides of the basin, with the western Pacific records concentrated in the marginal seas. Less is known about conditions in the central tropical Pacific. We have recently collected sediment cores spanning a range of latitude from $0.5^{\circ} \mathrm{S}$ to $7^{\circ} \mathrm{N}$ from the Line Islands Ridge located at approximately $155-160^{\circ} \mathrm{W}$ (Figure 1). At this longitude today, west of the equatorial cold tongue, the latitudinal and seasonal ranges of temperature and salinity are small [Schmidtko et al., 2013]. Temperature averages $27.1^{\circ} \mathrm{C}$ near the equator $\left(0.7^{\circ} \mathrm{C}\right.$ seasonal range) to $28^{\circ} \mathrm{C}\left(1^{\circ} \mathrm{C}\right.$ seasonal range) at $7^{\circ} \mathrm{N}$. Salinity averages 35.3 practical salinity unit ( $\mathrm{psu}$ ) near the equator ( $0.2 \mathrm{psu}$ seasonal range) to $34.6 \mathrm{psu}(0.5 \mathrm{psu}$ seasonal range) at $7^{\circ} \mathrm{N}$. The slightly cooler, saltier surface waters between $0^{\circ} \mathrm{N}$ and $4.5^{\circ} \mathrm{N}$ are supplied by equatorial upwelling and westward transport by the northern branch of the South Equatorial Current, and 


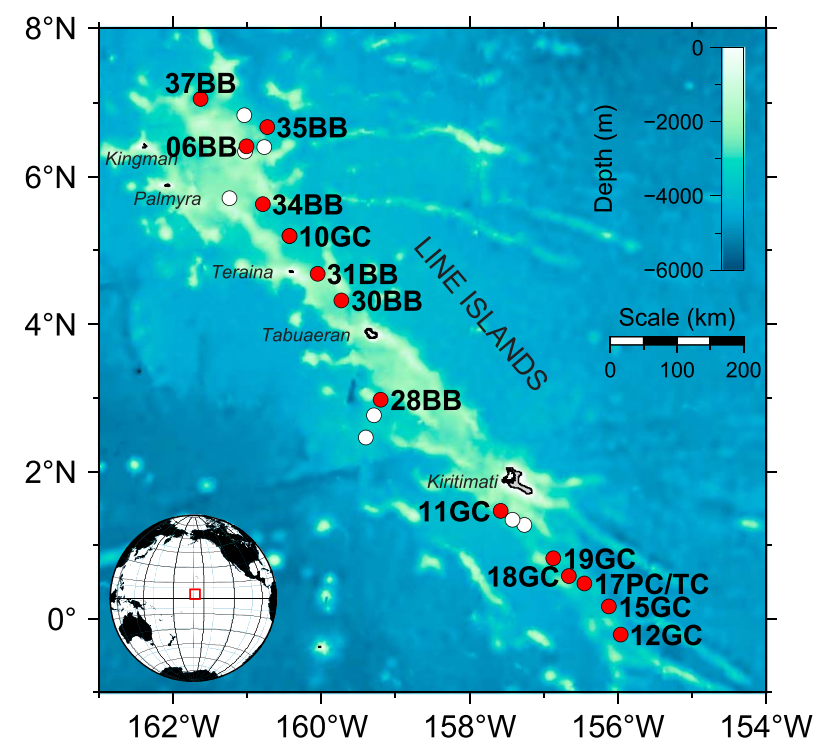

Figure 2. Bathymetric map showing location of sediment cores along the Line Island Ridge from cruise MGL1208. Red circles with labels indicate cores with oxygen isotope data discussed in this paper; white unlabeled circles are cores with MST data only. oxygen isotope values from benthic foraminifera [Lisiecki and Raymo, 2005]. We then consider all of the cores together, finding that the latitudinal gradient in G. ruber $\delta^{18} \mathrm{O}$ values was stronger during glacial times.

\section{Materials and Methods}

\subsection{Core Site Selection}

The Line Islands are a complex NW-SE trending chain of atolls, seamounts, and volcanic ridges in the central Pacific extending from the Mid-Pacific Mountains to the Tuamotu Plateau. In May 2012, cruise MGL1208 aboard the R/V Marcus Langseth investigated the central section of the Line Islands from $0^{\circ}$ to $10^{\circ} \mathrm{N}$, which is dominated by a continuous, relatively broad (100-300 km wide), volcanic ridge [Lynch-Stieglitz et al., 2012] (Figure 2). Above $2000 \mathrm{~m}$ water depth the plateau is covered by mostly smooth sediments characterized by low EM122 multibeam backscatter intensity and limited or no layering evident in the Knudsen Chirp subbottom profiler. These sediments contained evidence of strong current activity, including not only smooth surfaces but also sediment waves, and large sediment drifts in the lee of volcanic features. Attempts to core these sediments were not successful, and the limited material that was captured suggested that these sediments are composed primarily of winnowed foraminifera sands. The sediments below $2000 \mathrm{~m}$ water depths showed predominantly erosional features at the surface. The style of erosion varied from gently stepping incised terraces near the equator to more mature-looking dendritic channels further north (Figure 3). In general, the ridge tops showed low backscatter on the multibeam suggesting recent sedimentation, and the sides and bottoms of the channels showed higher backscatter intensities suggesting coarser sediment or sandy/harder ground. We chose most coring sites for gravity, piston, and multicores on local highs or ridges between the more deeply eroded channels at water depths of 2500-3500 m. Detailed bathymetry at the core locations is shown in the cruise report [Lynch-Stieglitz et al., 2012].

\subsection{Shipboard Stratigraphy}

Preliminary stratigraphies for all cores collected were constructed based on down-core bulk density estimates measured on a multisensor track (MST) system, and some basic biostratigraphic determinations. The pink-pigmented variety of the planktonic foraminifera G. ruber disappeared from the Pacific Ocean at $\sim 120$ ka [Thompson et al., 1979]. Therefore, the down-core appearance of G. ruber (pink) can be used as a stratigraphic datum marker for sediment cores from the Pacific. Based on this principle, we took samples from the core section breaks of all sediment cores taken on MGL1208. Samples were wet sieved through a $63 \mu \mathrm{m}$ mesh and dried. The samples were inspected for the presence of G. ruber (pink). In addition, the 

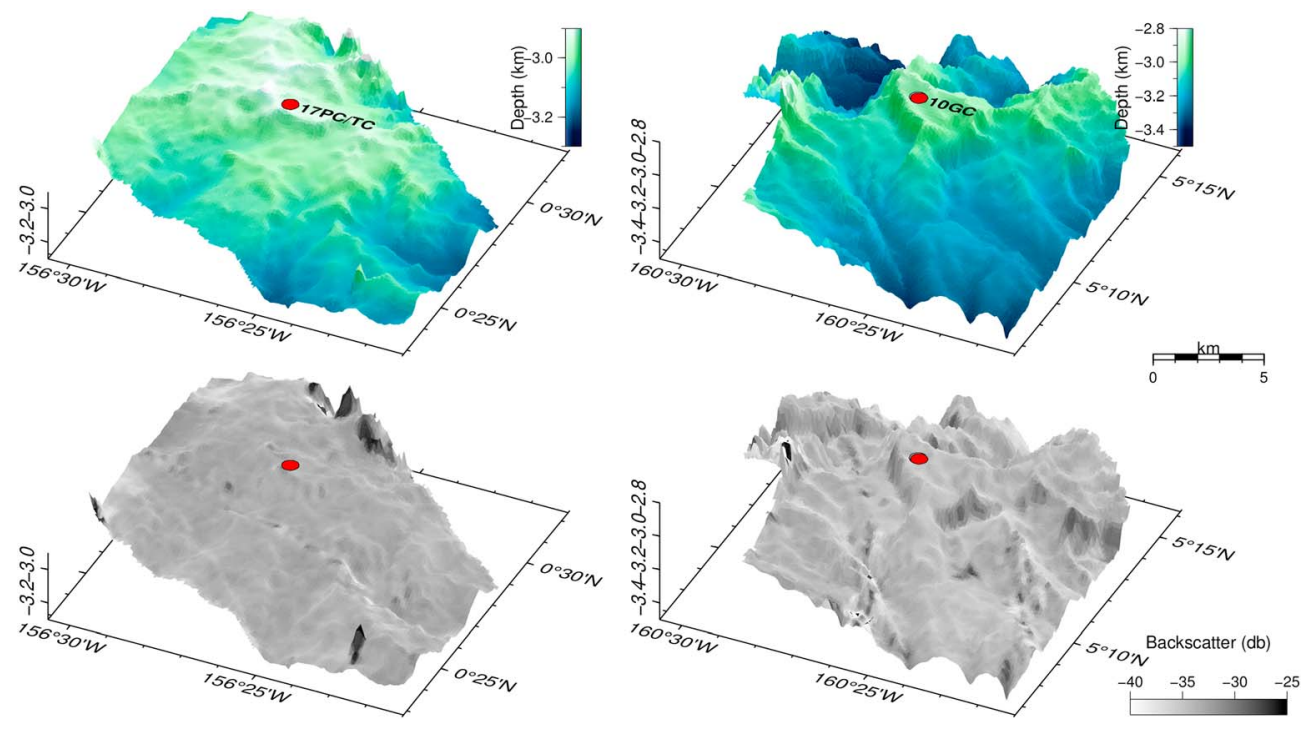

Figure 3. Multibeam bathymetry and backscatter of an equatorial (17PC, left) and more northerly (10GC, right) coring site. The northern sites have more distinctive erosional features including incised gullies with high (darker colored) multibeam backscatter indicating harder sediments.

presence of Globigerinoides fistulosus, a distinctive foraminifera which has a last appearance at $1.6 \mathrm{Ma}$ (near the Pliocene/Pleistocene boundary), was noted [Berggren et al., 1985]. Smear slides were examined at the bottom of each sediment core in order to determine the presence/absence of Discoaster, a marine haptophyte which has a last appearance at the Pliocene/Pleistocene boundary. The core break micropaleontological data that were used in constructing shipboard stratigraphies are tabulated in the cruise report [Lynch-Stieglitz et al., 2012].

The Geotek multisensor track system was used to measure bulk sediment physical properties every $1 \mathrm{~cm}$ on whole core sections. Gamma attenuation counts made for bulk density were calibrated before scanning each core using an aluminum block of varying thickness submerged in distilled water. Gamma attenuation counts were collected for $5 \mathrm{~s}$ at each interval and corrected for nonstandard core thickness. The bulk density curve was coherent between core sites and was used to correlate the cores on board, and the appearance of $G$. ruber (pink) was used to assign an absolute age to the bulk density curve.

\subsection{Postcruise Analyses}

A subset of sediment cores was selected for down-core oxygen isotope stratigraphies on the planktonic foraminifera G. ruber (white). Cores were chosen to maximize the available stratigraphic information from the cores collected during MGL1208, rather than to select for the cores with the most promise for paleoceanographic study. We established two benchmark cores located in the southern and northern portions of the transect: 17PC and 37BB. As measured using the MST, these cores had density changes with depth that were typical for the cores taken during the cruise. These cores were sampled at $4 \mathrm{~cm}$ intervals from top to bottom. All cores that had a clear match in MST density with the benchmark cores were not sampled and analyzed for oxygen isotopes. Rather, the remaining cores that did not have a clear match in MST density with the benchmark cores yet appeared to be late Pleistocene in age were analyzed over the top $240 \mathrm{~cm}$ of the core at $4 \mathrm{~cm}$ intervals.

Some of these cores were processed and analyzed at Georgia Institute of Technology, and some at Lamont-Doherty Earth Observatory (Table 1). At Georgia Institute of Technology, samples were dried overnight at $65^{\circ} \mathrm{C}$, weighed, and washed through a $63 \mu \mathrm{m}$ sieve with deionized water, and the washed samples were then dried overnight at $65^{\circ} \mathrm{C}$. Fifteen specimens of $G$. ruber (white) were picked from the 250-355 $\mu \mathrm{m}$ sieve size fraction, weighed on a Cahn Ultra C35 Microbalance, and analyzed on a Thermo MAT253 with Kiel IV individual acid bath device. Values were converted to Vienna Peedee belemnite (VPDB) via NBS-19 and an in-house standard, and NBS-18 values were monitored in each run. Replicate analyses of the in-house standard mixed in the sample runs yielded a 1 sigma standard deviation of $0.045 \%$ for $\delta^{18} \mathrm{O}$ and 


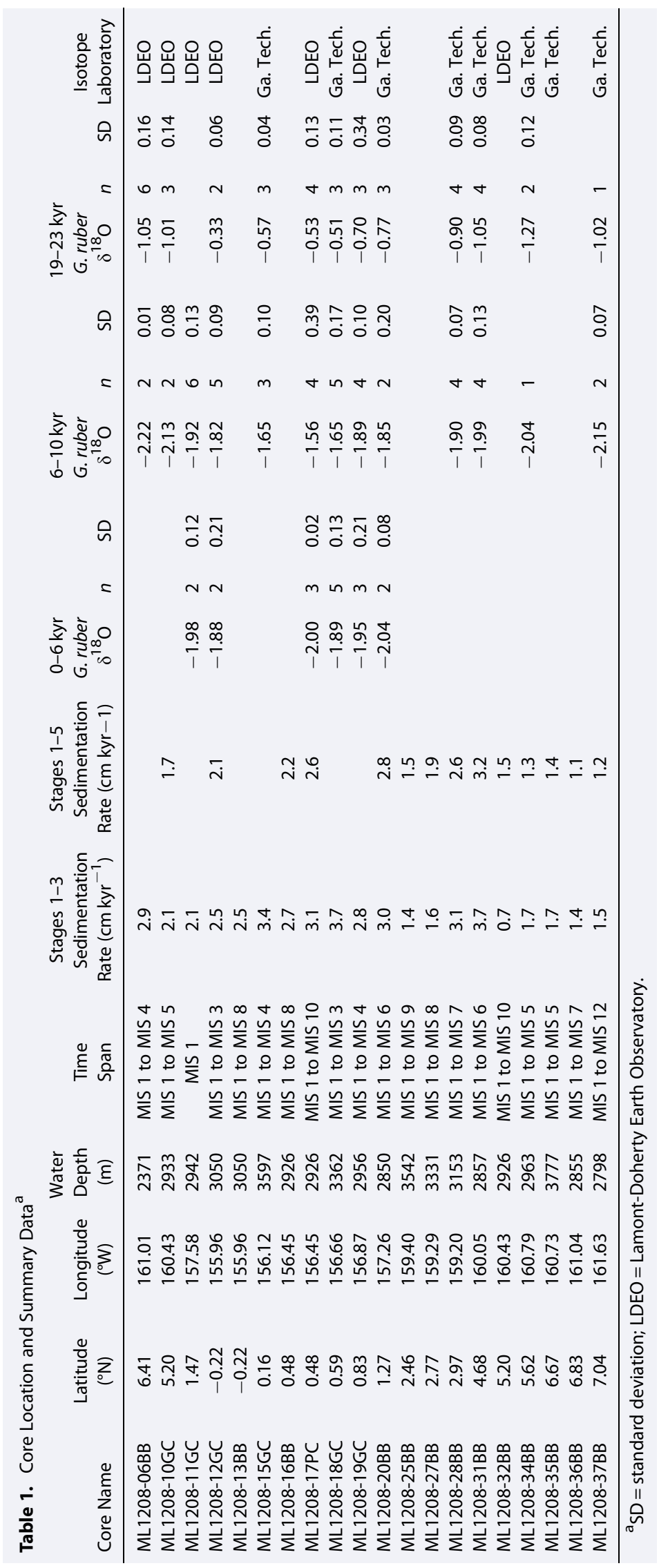


$0.014 \%$ for $\delta^{13} \mathrm{C}$. The high external precision is a function of the relatively narrow range of sample and standard masses in these runs ( $163 \mu \mathrm{g}$ with a 1 sigma standard deviation of $23 \mu \mathrm{g})$.

Samples processed and analyzed at Lamont-Doherty Earth Observatory were freeze dried and washed through a $63 \mu \mathrm{m}$ sieve, and the $>63 \mu \mathrm{m}$ fraction dried at $45^{\circ} \mathrm{C}$ overnight. Seven or eight specimens of G. ruber (white) were picked from the 250-355 $\mu \mathrm{m}$ size fraction, weighed, and analyzed on a Thermo Delta $V$ Plus with Kiel IV individual acid bath device. Values were calibrated to the VPDB isotope scale with NBS-19 and NBS-18. Reproducibility of the in-house standard (1 sigma) is $\pm 0.06 \%$ o $\left(\delta^{18} \mathrm{O}\right)$ and $\pm 0.04 \% \circ\left(\delta^{13} \mathrm{C}\right)$.

An additional set of stable isotope analyses was made on planktonic foraminifera from core top samples that were taken from all gravity and piston sediment cores during the cruise. G. ruber (white) of the variants sensu stricto and sensu lato [Steinke et al., 2005; Wang, 2000] were picked from the 250-355 $\mu \mathrm{m}$ sieve size fraction, Globigerinoides sacculifer (without sac chamber) from the 355-425 $\mu \mathrm{m}$ and 500-850 $\mu \mathrm{m}$ size fractions, Globorotalia tumida from the $425-500 \mu \mathrm{m}$ size fraction, and Neoglobquadrina dutertrei from the 355-425 $\mu \mathrm{m}$ size fraction. The G. ruber and smaller G. sacculifer were analyzed in groups of 15 specimens, five specimens were analyzed individually for the larger $G$. sacculifer, and eight specimens of $G$. tumida and $N$. dutertrei were analyzed individually. All of these additional core top measurements were made at Georgia Institute of Technology.

All radiocarbon dates reported here were measured th the National Ocean Sciences Accelerator Mass Spectrometry facility at Woods Hole Oceanographic Institution, and either G. ruber or G. sacculifer picked from the $250-500 \mu \mathrm{m}$ sieve size fraction were analyzed. Radiocarbon dates were converted to calendar age using CALIB7.0 and the standard marine calibration curve (MARINE13) with no additional reservoir age correction [Reimer et al., 2013].

\section{Results}

The MST density data and down-core G. ruber $\delta^{18} \mathrm{O}$ for all sediment cores are shown in Figure S1 in the supporting information and archived at the World Data Center for Paleoclimatology at the National Climate Data Center (http://hurricane.ncdc.noaa.gov/pls/paleox/f?P=519:1::.:.:P1_STUDY_ID:1001374). Marine Isotope Stage (MIS) boundaries are assigned based on correlation of the oxygen isotope data to the global benthic stack of Lisiecki and Raymo [2005], or in the absence of oxygen isotope data, by correlating the MST density data to cores with oxygen isotope data. The two sediment cores that were used to establish the link between the MST density and oxygen isotope stratigraphy are shown in Figure 4. The assignment of the depth of the stage boundaries should be considered preliminary. The changes in oxygen isotope ratio in planktonic foraminifera for these cores might show leads or lags relative to the global benthic foraminiferal stack on the order of several thousand years. The age models for these cores will be refined in further studies with more detailed radiocarbon dating and oxygen isotope analysis on benthic foraminifera.

Radiocarbon measurements are presented in Table 2, and core top $\delta^{18}$ O measurements from multiple species of planktonic foraminifera are presented in Tables 3 and S1.

\section{Discussion}

\subsection{Deposition and Erosion}

Erosional features dominate the sediments below $2000 \mathrm{~m}$ on the Line Islands Ridge. Most of the sites that we chose to core were on local highs (ridges between erosional channels), and most of these sites yielded an intact late Quaternary stratigraphy. However, for some cores (e.g., 20BB, 31BB, and 36BB, Figure S1) the recovered Quaternary section was deposited on top of a hiatus with much older sediments below as evidenced by the presence of Discoaster or G. fistulosus. In other cores, the stratigraphy is interrupted by coarse layers, presumably turbidite deposits (e.g., 28BB, 34BB, and 35BB, Figure S1). Based on the multichannel seismic reflection data collected during the cruise [Lynch-Stieglitz et al., 2012] and the surface morphology, we would expect that deeper coring or drilling at all locations would eventually encounter multiple hiatuses. The sedimentation rates for the intact late Quaternary sediments are, for the most part, consistent with expectations for open ocean pelagic sedimentation with higher accumulation rates $\left(3 \mathrm{~cm} \mathrm{kyr}^{-1}\right)$ near the equator reflecting the enhanced flux of biological detritus and lower rates $\left(1 \mathrm{~cm} \mathrm{kyr}^{-1}\right)$ 
a) ML1208-17PC $0.48^{\circ} \mathrm{N} 2926 \mathrm{~m}$
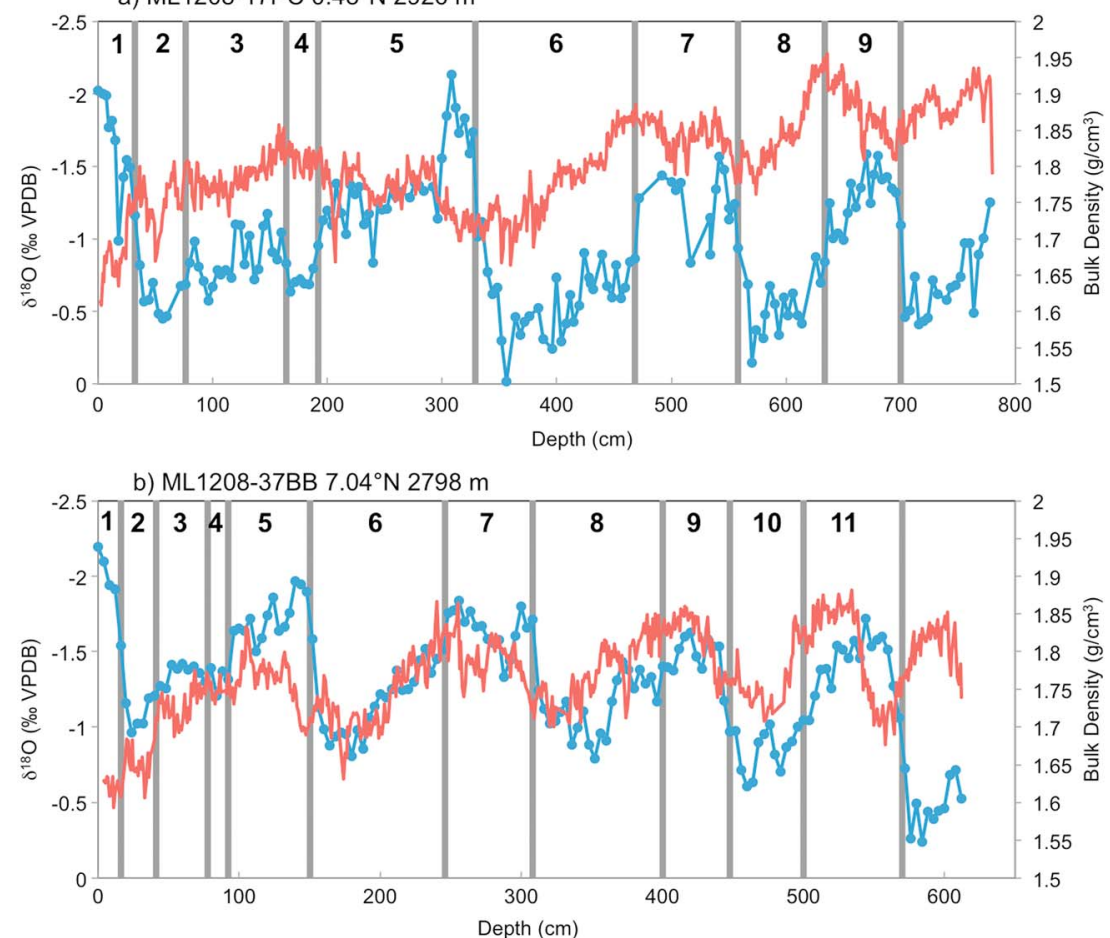

Figure 4. (a) Bulk density as measured by MST (red line); oxygen isotope composition of G. ruber (blue symbols) for equatorial sediment core MGL1208-17PC. Marine Isotope Stage (MIS) boundaries are indicated. (b) Same for more northern core MGL1208-37BB.

to the north (Figure 5). These data collectively point to the Line Islands Ridge as a dynamic feature on longer time scales-accumulating biogenic sediment that periodically becomes unstable and is sloughed off through the drainage channels apparent in the surface morphology. Net accumulation over much

Table 2. Radiocarbon Dates ${ }^{\mathrm{a}}$

\begin{tabular}{|c|c|c|c|c|c|}
\hline Core & Depth in Core $(\mathrm{cm})$ & Species & ${ }^{14} \mathrm{C}$ Age (years) & Error & Calendar Age (years) \\
\hline ML1208-10GC & 0 & G. ruber & 10,650 & 45 & 11,994 \\
\hline ML1208-13BB & 0 & G. ruber & 4,780 & 45 & 5,049 \\
\hline ML1208-15GC & 0 & G. ruber & 7,150 & 45 & 7,618 \\
\hline ML1208-18GC & 0 & G. sacculifer & 3,320 & 45 & 3,167 \\
\hline ML1208-18GC & 16 & G. ruber & 5,530 & 60 & 5,916 \\
\hline ML1208-18GC & 32 & G. ruber & 8,900 & 55 & 9,552 \\
\hline ML1208-18GC & 48 & G. ruber & 9,800 & 40 & 10,713 \\
\hline ML1208-18GC & 60 & G. ruber & 13,750 & 90 & 16,053 \\
\hline ML1208-18GC & 68 & G. ruber & 15,250 & 60 & 18,052 \\
\hline ML1208-18GC & 112 & G. ruber & 28,500 & 130 & 31,844 \\
\hline ML1208-18GC & 140 & G. ruber & 33,200 & 250 & 36,795 \\
\hline ML1208-19GC & 0 & G. ruber & 3,120 & 35 & 2,895 \\
\hline ML1208-20BB & 0 & G. ruber & 3,860 & 30 & 3,823 \\
\hline ML1208-27BB & 0 & G. ruber & 5,550 & 45 & 5,937 \\
\hline ML1208-31BB & 0 & G. ruber & 11,200 & 60 & 12,689 \\
\hline ML1208-31BB & 4 & G. ruber & 6,700 & 45 & 7,231 \\
\hline ML1208-31BB & 12 & G. ruber & 6,280 & 50 & 6,735 \\
\hline ML1208-31BB & 40 & G. ruber & 11,550 & 45 & 13,030 \\
\hline ML1208-31BB & 72 & G. ruber & 17,450 & 75 & 20,560 \\
\hline ML1208-34BB & 0 & G. ruber & 8,540 & 45 & 9,173 \\
\hline ML1208-37BB & 0 & G. ruber & 6,180 & 35 & 6,619 \\
\hline
\end{tabular}

${ }^{\mathrm{a}}$ Radiocarbon dates calibrated using CALIB7.0 with standard marine reservoir correction. 
Table 3. Multispecies Core Top Isotope Data ${ }^{a}$

\begin{tabular}{|c|c|c|c|c|c|c|c|c|c|c|c|c|c|c|c|c|}
\hline \multirow[b]{2}{*}{ Core } & \multicolumn{2}{|c|}{$\begin{array}{l}\text { G. ruber s.s. } \\
250-355 \mu \mathrm{m}\end{array}$} & \multicolumn{2}{|c|}{$\begin{array}{l}\text { G. ruber s.l. } \\
250-355 \mu \mathrm{m}\end{array}$} & \multicolumn{2}{|c|}{$\begin{array}{c}\text { G sacculifer } \\
355-425 \mu \mathrm{m}\end{array}$} & \multicolumn{2}{|c|}{$\begin{array}{l}\text { G. sacculifer } \\
>500 \mu \mathrm{m}\end{array}$} & \multicolumn{4}{|c|}{$\begin{array}{l}\text { N. dutertrei } \\
355-425 \mu \mathrm{m}\end{array}$} & \multicolumn{4}{|c|}{$\begin{array}{l}\text { G. tumida } \\
425-500 \mu \mathrm{m}\end{array}$} \\
\hline & $\delta^{18} \mathrm{O}$ & $\delta^{13} \mathrm{C}$ & $\delta^{18} \mathrm{O}$ & $\delta^{13} \mathrm{C}$ & $\delta^{18} \mathrm{O}$ & $\delta^{13} \mathrm{C}$ & $\delta^{18} \mathrm{O}$ & $\delta^{13} \mathrm{C}$ & $\delta^{18} \mathrm{O}$ & s.e. & $\delta^{13} \mathrm{C}$ & s.e. & $\delta^{18} \mathrm{O}$ & s.e. & $\delta^{13} \mathrm{C}$ & s.e. \\
\hline ML1208-06BB & -2.00 & 1.12 & & & -1.79 & 1.89 & & & -0.85 & 0.25 & 1.46 & 0.12 & -0.81 & 0.13 & 1.68 & 0.07 \\
\hline ML1208-10GC & -1.67 & 1.14 & -1.77 & 1.00 & -1.72 & 1.42 & -1.68 & 1.91 & -1.15 & 0.17 & 1.61 & 0.09 & 0.19 & 0.21 & 1.77 & 0.09 \\
\hline ML1208-11GC & -1.85 & 1.37 & & & -1.49 & 1.57 & & & -0.56 & 0.12 & 1.60 & 0.08 & -0.17 & 0.25 & 1.71 & 0.08 \\
\hline ML1208-12GC & -1.90 & 1.12 & & & -1.67 & 1.55 & & & -0.57 & 0.12 & 1.63 & 0.06 & -0.55 & 0.13 & 2.03 & 0.05 \\
\hline ML1208-13BB & -1.91 & 1.14 & & & -1.71 & 1.33 & -1.65 & 2.02 & -0.66 & 0.15 & 1.71 & 0.07 & -0.52 & 0.13 & 1.94 & 0.04 \\
\hline ML1208-15GC & -1.76 & 1.39 & -2.01 & 1.10 & -1.39 & 1.35 & -1.51 & 1.61 & -0.37 & 0.14 & 1.71 & 0.08 & -0.32 & 0.09 & 1.87 & 0.07 \\
\hline ML1208-16BB & -2.00 & 1.29 & & & -1.61 & 1.44 & & & -0.73 & 0.18 & 1.63 & 0.04 & -0.33 & 0.17 & 1.94 & 0.06 \\
\hline ML1208-17TC & -2.08 & 1.44 & -2.03 & 1.27 & -1.49 & 1.22 & -1.79 & 1.55 & -0.41 & 0.18 & 1.51 & 0.03 & -0.56 & 0.10 & 1.91 & 0.05 \\
\hline ML1208-18GC & -2.10 & 1.24 & & & -1.61 & 1.39 & -1.84 & 2.06 & -0.47 & 0.12 & 1.54 & 0.03 & -0.41 & 0.15 & 1.89 & 0.09 \\
\hline ML1208-19GC & -2.04 & 1.24 & -1.94 & 1.16 & -1.71 & 1.34 & -1.77 & 1.61 & -0.50 & 0.13 & 1.59 & 0.04 & -0.51 & 0.19 & 1.83 & 0.06 \\
\hline ML1208-20BB & -2.10 & 1.47 & -2.12 & 1.16 & -1.71 & 1.55 & -1.91 & 1.92 & -0.94 & 0.14 & 1.66 & 0.08 & -0.82 & 0.12 & 1.92 & 0.06 \\
\hline ML1208-25BB & & & -1.49 & 1.12 & -1.84 & 1.35 & & & -0.72 & 0.23 & 1.56 & 0.05 & -0.57 & 0.22 & 1.76 & 0.03 \\
\hline ML1208-27BB & -2.07 & 1.32 & & & -1.88 & 1.34 & & & -0.92 & 0.18 & 1.48 & 0.09 & -0.79 & 0.14 & 1.85 & 0.03 \\
\hline ML1208-28BB & -1.74 & 1.28 & & & -1.92 & 1.64 & & & -0.82 & 0.13 & 1.44 & 0.08 & -0.58 & 0.18 & 1.73 & 0.09 \\
\hline ML1208-31BB & -1.84 & 1.28 & -1.81 & 1.17 & -1.56 & 1.67 & -1.84 & 1.89 & -0.71 & 0.26 & 1.58 & 0.04 & -0.86 & 0.14 & 1.81 & 0.07 \\
\hline ML1208-34BB & -1.76 & 1.27 & -2.09 & 1.04 & -1.88 & 1.74 & -1.91 & 1.49 & & & & & -1.05 & & 1.97 & \\
\hline ML1208-35BB & -1.34 & 0.95 & & & -1.55 & 1.20 & & & -0.64 & 0.22 & 1.09 & 0.09 & -0.05 & 0.20 & 1.81 & 0.12 \\
\hline ML1208-36BB & -1.98 & 1.25 & -1.91 & 1.13 & -1.91 & 1.56 & -2.07 & 1.93 & -0.87 & 0.37 & 1.49 & 0.11 & -0.42 & 0.25 & 1.67 & 0.10 \\
\hline ML1208-37BB & -2.26 & 1.23 & -2.22 & 1.01 & -1.77 & 1.59 & -2.02 & 1.63 & -1.67 & 0.12 & 1.89 & 0.13 & -0.40 & 0.25 & 1.84 & 0.09 \\
\hline
\end{tabular}

${ }^{\mathrm{a}}$ Standard error $=$ s.e.

longer timescales has occurred, as indicated by thick sediment packages identified in the multichannel seismic reflection data [Lynch-Stieglitz et al., 2012]. However, these packages are composed of discontinuous layers likely formed by aggradation of channel lag deposits in a dynamic, erosional environment.

\subsection{Carbonate Preservation}

The late Quaternary sediment cores show regionally coherent cycles in bulk density as measured by MST (Figures 4 and S1). These variations in bulk density seem to reflect the well-known Pacific carbonate cycles that appear in deep sediment cores throughout the Pacific [e.g., Berger, 1973; Farrell and Prell, 1991; Lalicata and Lea, 2011], with low-sediment density corresponding the time intervals of enhanced carbonate accumulation in Pacific sediments. The percent of sediment that is coarser than $63 \mu \mathrm{m}$ has been used as a proxy for dissolution in open ocean carbonate-rich sediments [Broecker and Clark, 1999], and in these cores corresponds well to sediment density with the exception of the very top of the cores (Figure 6a). Increased dissolution will cause the breakage of foraminifera, transferring the carbonate material from the coarse to the fine fraction of the sediment. The increased number of fragments relative to whole shells results in more dense sediments upon burial and compaction. While an increase in coarse fraction could also potentially be caused by increased winnowing of fine fraction by deep currents, or alternatively by a decrease in shell breakage due to weaker bottom currents, the regional coherency of the signal from the equator to $7^{\circ} \mathrm{N}$, and with other locations in the Pacific, would argue for the link to carbonate preservation/dissolution cycles.

Another potential indicator of dissolution is the average shell mass of foraminifera of a given species and size [Broecker and Clark, 2001]. The measured shell mass of G. ruber from the 250-355 $\mu \mathrm{m}$ size fraction is relatively constant down core $(11.5 \pm 0.7 \mathrm{mg}$ for $37 \mathrm{BB})$ and is not correlated to either the coarse fraction or the bulk density (Figure 6b). The measured shell mass is consistent with that expected for $G$. ruber from a sediment core close to the saturation horizon [de Villiers, 2005]. The shell mass is also relatively constant between cores over the range of water depths sampled during the cruise (Figure 7) but does show some indication that shell mass is being lost to dissolution for deeper cores. The relatively constant shell mass measurements suggest that changes in dissolution are unlikely to be a major influence on the down-core G. ruber oxygen records presented in this paper or be driving the spatial gradients between cores from different depths and latitudes. However, other geochemical proxies may be affected by the changes in dissolution both with depth and through time. 

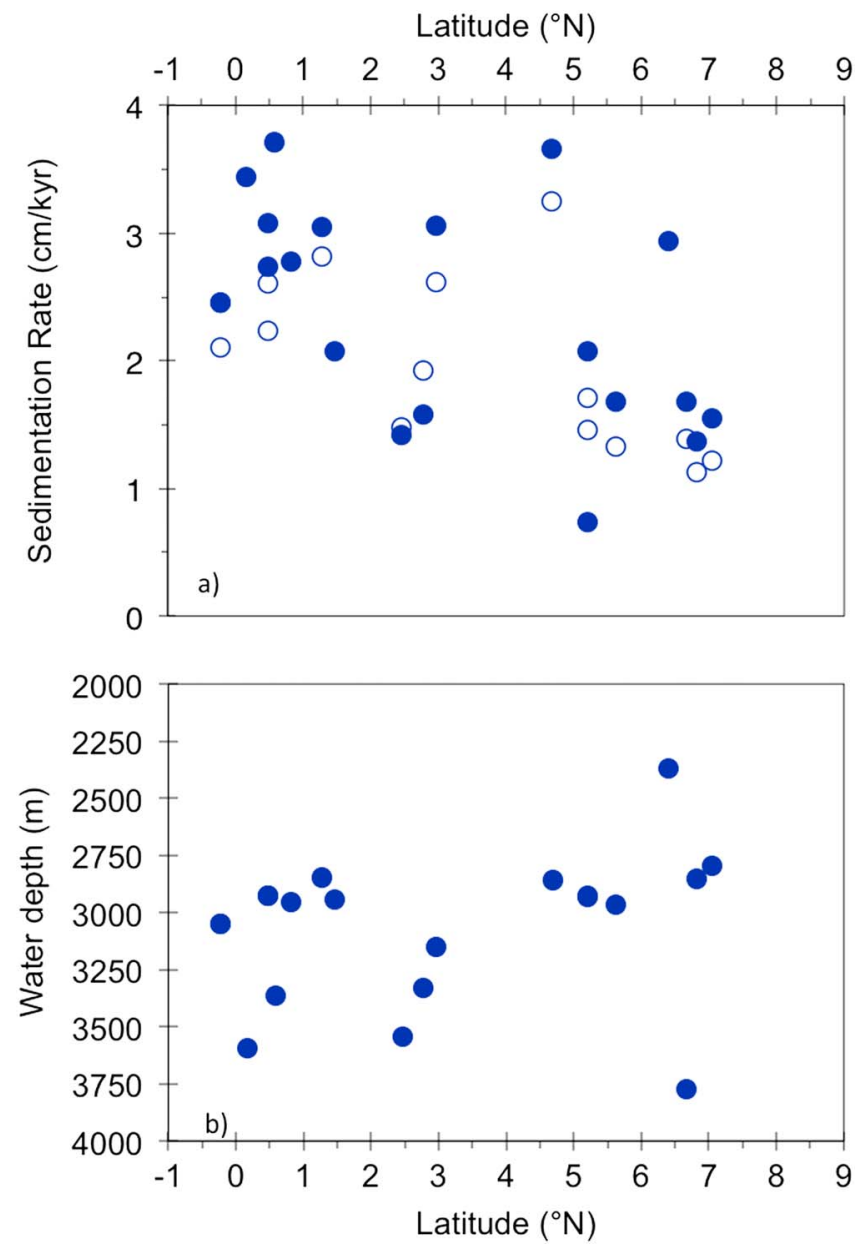

Figure 5. (a) Sedimentation rate for all cores where stratigraphy could be determined from oxygen isotope or MST data versus core latitude (Figure S1). Solid symbols are sedimentation rate to the MIS 3/4 boundary. Open symbols are sedimentation rate to the MIS 5/6 boundary. (b) Core water depth versus latitude for cores with determined stratigraphy.

\subsection{Core Top Radiocarbon and Oxygen Isotope Anomalies}

For some cores (10GC, 28BB, 31BB, 34BB, and $35 \mathrm{BB}$ ) we observe anomalously positive $G$. ruber $\delta^{18} \mathrm{O}$ values for the upper few centimeters in the core. For the cores where we have measured both G. ruber $\delta^{18} \mathrm{O}$ and radiocarbon (Table 2), the positive core top G. ruber $\delta^{18} O$ values are all associated with older $G$. ruber radiocarbon dates. This suggests that the high $\delta^{18} \mathrm{O}$ results from the presence of foraminifera from older time periods at the top of the core. However, below the anomalous surface $\delta^{18} \mathrm{O}$, a normal down-core progression from expected Holocene to glacial $\delta^{18} \mathrm{O}$ values is found. For core 31BB (Figure 8), we have down-core radiocarbon dates that show an age reversal at the core top, but a return to the normal progression toward older dates down core. One of the cores with a surface $\delta^{18} \mathrm{O}$ anomaly (35BB) is much deeper than the others (3777 m), and heavy dissolution is thus expected. However, the other cores with high core top $\delta^{18} \mathrm{O}$ values (10GC, $28 \mathrm{BB}, 31 \mathrm{BB}$, and $34 \mathrm{BB}$ ) are no deeper than those with no core top $\delta^{18} \mathrm{O}$ maximum. There is also no apparent relationship between the presence of a core top $\delta^{18} \mathrm{O}$ maximum and sedimentation rate or average fraction of the sediment $>63 \mu \mathrm{m}$ (a potential indicator of dissolution). All of the

affected cores are north of $2^{\circ} \mathrm{N}$. It is not clear what causes these core top reversals, but given the relatively modest sedimentation rates north of $2^{\circ} \mathrm{N}$, bioturbation and selective dissolution of foraminifera within the sediment are mechanisms that could potentially contribute. Berelson et al. [1997] find evidence for a recent increase in dissolution in deeper sediments at similar latitudes at $140^{\circ} \mathrm{W}$ and suggest that it was driven by a decrease in the carbonate ion concentration over the last $3 \mathrm{kyr}$. More detailed radiocarbon measurements would be necessary to solve this mystery.

It is noteworthy that core top ages increase to the north as sedimentation rates decrease, suggesting the coupled action of bioturbation and dissolution of younger foraminifera as is seen on the Ontong Java Plateau in the Western Tropical Pacific [Broecker et al., 1999]. Broecker et al. [1999] observe a similar trend of younger core top radiocarbon ages nearer to the equator on the Ontong Java Plateau.

\subsection{Core Top Stable Isotope Data}

The primary aim of our core top measurements was to determine which species (or variant) best represents surface mixed layer conditions. We can assess the apparent calcification depth by comparing the isotopic composition of the foraminiferal calcite with that expected at various depths in the water column. The $\delta^{18} \mathrm{O}$ of the foraminifera reflects the $\delta^{18} \mathrm{O}$ of the seawater in which it calcifies, and the temperature of calcification. Different formulations of the temperature-dependent isotopic fractionation between oxygen isotopes in foraminiferal calcite and seawater have been developed for different species based on culture experiments, 

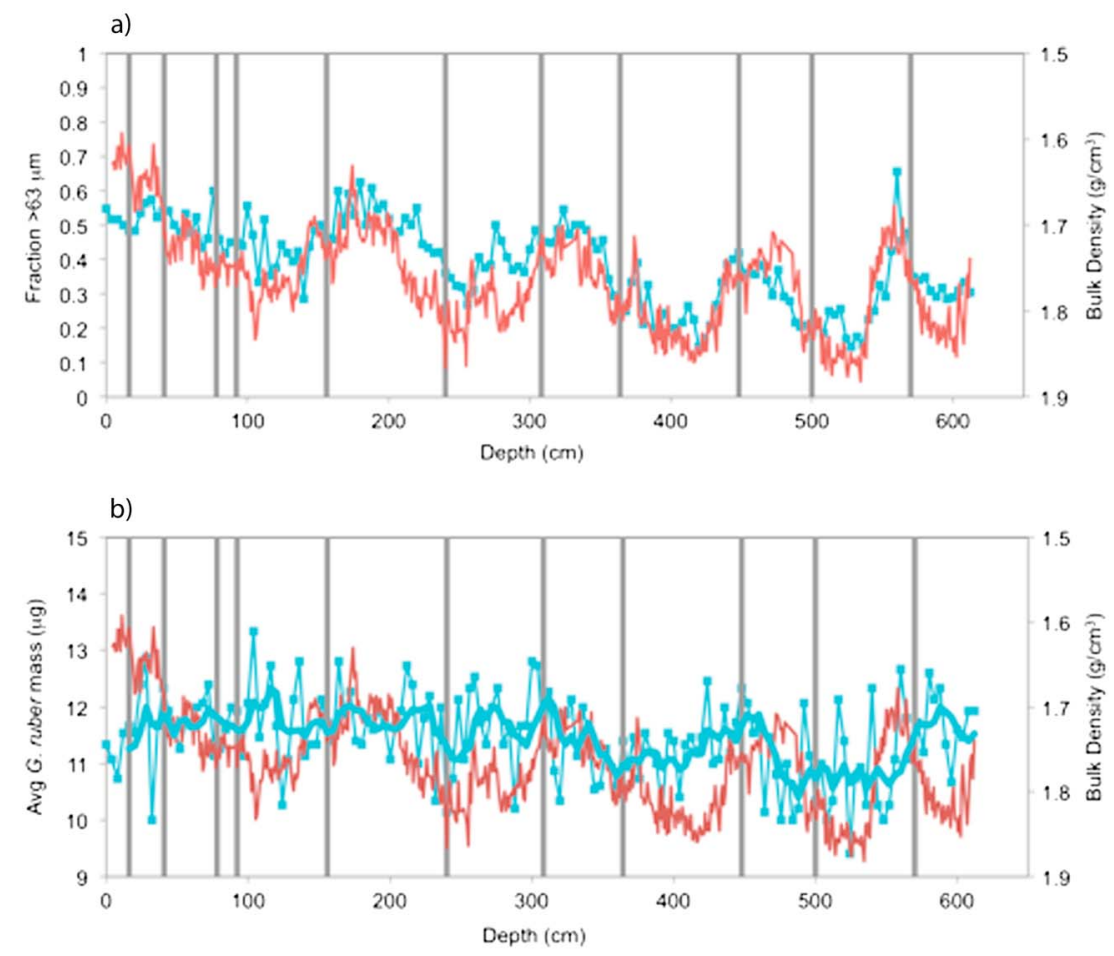

Figure 6. (a) Bulk density as measured by MST (red line) and fraction of sediment by weight that is greater than $63 \mu \mathrm{m}$ sieve size (light blue line and symbols) for core ML1208-37BB $\left(7.04^{\circ} \mathrm{N} 2798 \mathrm{~m}\right)$. Marine Isotope Stage boundaries (Figure 4) are indicated with the vertical grey lines. (b) Bulk density as measured by MST (red line) and the average shell weight of the 20 individual G. ruber selected for isotopic analysis (light blue line and symbols). The thick blue line is a five-point moving average of the shell weight measurements.

field sampling, and surface sediments. However, many of these relationships fall close to that developed for inorganic calcite by Kim and O'Neil [1997] [Bemis et al., 1998; Rincon-Martinez et al., 2011], and so we use this relationship to define the expected isotopic composition for different water column depths (Figure 9).

Both G. ruber and G. sacculifer have photosynthetic algal symbionts, so they must spend most of their life near the sea surface. G. ruber is often analyzed to reconstruct surface conditions as it not only puts on its primary calcite in the surface mixed layer but does not appear to add calcite at deeper depths during gametogenesis like some other species. However, it has been found that different morphotypes of G. ruber yield different oxygen and carbon isotope values as well as different $\mathrm{Mg} / \mathrm{Ca}$ ratios in the South China Sea [Steinke et al., 2005; Wang, 2000]. We analyzed separately the more abundant G. ruber sensu stricto (s.s.) and the less abundant and more compact G. ruber sensu lato (s.l.) as defined by these authors. We find that there is no significant difference in the oxygen isotopic composition of these two morphotypes in our core tops (Figure 9). However, the $\delta^{13} \mathrm{C}$ of G. ruber s.l. was lower than G. ruber s.s. in all cases (Table 3, mean difference $=0.19 \% 0 \pm 0.0831$ sigma standard deviation). Our $\delta^{18} \mathrm{O}$ and $\delta^{13} \mathrm{C}$ observations are similar to a recent study on sediment trap, core top and down-core samples from the Gulf of Mexico that found no significant differences between G. ruber morphotypes [Thirumalai et al., 2014]. As G. ruber is very abundant in these sediments, and G. ruber s.s. is the most abundant variant, the vast majority of G. ruber analyzed in the down-core records presented here were likely G. ruber s.s.

When we disregard the core tops between 4 and $6^{\circ} \mathrm{N}$ which have old radiocarbon ages, most G. ruber show apparent calcification depths within the surface mixed layer (Figure 9). Because of the issues described in section 4.3, some of the other core tops showing deeper apparent calcification depths, particularly in the northern part of the transect, likely contain pre-Holocene foraminifera which would have higher $\delta^{18} \mathrm{O}$.

In culture experiments, Spero and Lea [1993] find that G. sacculifer test size is sensitive to light level, with high light conditions yielding larger specimens. Spero et al. [2003] find that in the eastern equatorial Pacific, large $(>650 \mu \mathrm{m})$ specimens of $G$. sacculifer have $\delta^{18} \mathrm{O}$ very similar to $G$. ruber suggesting a surface habitat, whereas 


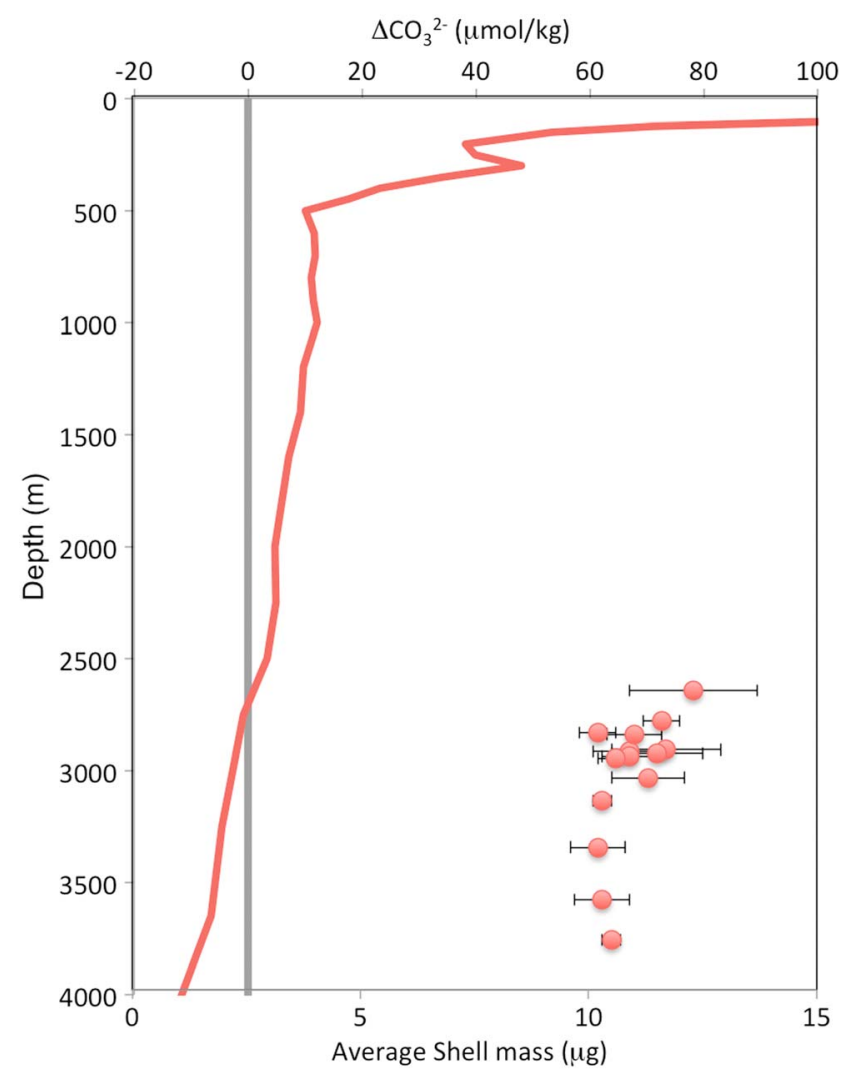

Figure 7. Carbonate saturation versus depth (red line) near the Line Islands Ridge based on water column data from the WOCE Hydrographic Program cruise $\mathrm{P} 16 \mathrm{~N}$ at $3^{\circ} \mathrm{N}, 151^{\circ} \mathrm{W}$ (http://cchdo.ucsd.edu). Also shown is the average mass of $G$. ruber $(250-355 \mu \mathrm{m})$ from the top $40 \mathrm{~cm}$ of the sediment cores (red circles). Error bars are the standard error of the mean ( 2 sigma) of the shell mass measurements. smaller specimens $(250-350 \mu \mathrm{m})$ have a higher $\delta^{18} \mathrm{O}$ indicating a deeper calcification depth. Here we find support for this idea, with the larger G. sacculifer specimens showing a lower $\delta^{18} \mathrm{O}$ and a shallower inferred calcification depth. However, for both the smaller and larger G. sacculifer, $\delta^{18} \mathrm{O}$ is higher than that of G. ruber, suggesting that even the larger specimens have significant calcite added below the surface. The implied calcification depth for $G$. sacculifer is between the surface mixed layer and $100 \mathrm{~m}$ water depth in the upper thermocline. Both G. tumida and $N$. dutertrei show deeper apparent calcification depths between 100 and $140 \mathrm{~m}$ (midthermocline).

Using a similar approach and a set of core top samples in the eastern tropical Pacific, Rincon-Martinez et al. [2011] find that $G$. ruber (both sensu stricto and sensu lato) calcify between 0 and $50 \mathrm{~m}$ water depth, whereas $\mathrm{G}$. sacculifer (0-100 m), N. dutertrei (50-250 m), and G. tumida (50-300 $\mathrm{m}$ ) acquire their calcite deeper in the water column. Plankton tow studies of the depth distribution of living foraminifera also suggest a shallow mixed layer habitat depth for G. ruber, slightly deeper mixed layer range for G. sacculifer, and thermocline habitats for

N. dutertrei and G. tumida [Fairbanks et al., 1982; Ravelo and Fairbanks, 1992]. Plankton tows from $140^{\circ} \mathrm{W}$ in the central tropical Pacific, very near to our study area, concur with inferred mixed layer habitats for $G$. sacculifer and G. ruber, with both of these species present in significant numbers over the entire latitudinal range of our study during both El Niño and La Niña conditions [Watkins et al., 1996, 1998]. This would suggest that these species will record conditions without a strong bias toward more oligotrophic conditions. Watkins et al. [1998] find a subsurface habitat for G. tumida south of the equator, but they find that north of the equator N. dutertrei and G. tumida are abundant in the surface mixed layer [Watkins et al., 1996, 1998] in contrast to the inference of a deeper habitat based on oxygen isotope data.

\subsection{Assessing Meridional Gradients}

\subsubsection{Oxygen Isotope-Based Age Models}

In order to assess how the meridional gradients in G. ruber $\delta^{18} \mathrm{O}$ have changed with time, we must first assign age models to the records. Age models were developed by linearly interpolating between age control points that were chosen as described below and are summarized in Table S2. For the cores that showed minimum $\delta^{18} \mathrm{O}$ values at the core top, the core top radiocarbon date converted to calendar years was used as the core top age. Where no core top radiocarbon date was available, we assumed that the core top age was similar to neighboring cores. For cores south of $2^{\circ} \mathrm{N}$ without core top radiocarbon dates, we used the average core top dates of the three cores that had core top radiocarbon measurements, 3734 calendar years B.P. For core 06BB, we assign the core top age from nearby core 37BB.

For those cores between 3 and $6^{\circ} \mathrm{N}$ that showed a core top radiocarbon reversal or $\delta^{18} \mathrm{O}$ reversal (see section 4.3.) we did not assign an age to the core top but assigned an age to the depth of the minimum Holocene $\delta^{18} \mathrm{O}$ 

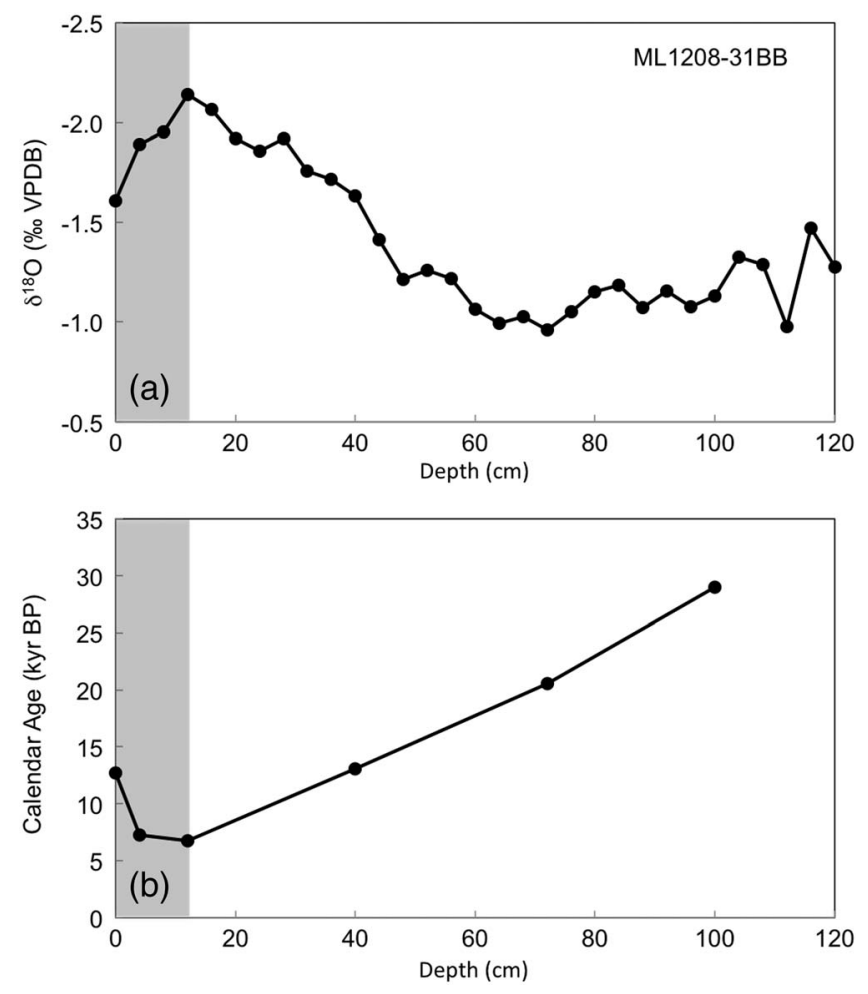

Figure 8. Detail showing the down-core progression of (a) the $\delta^{18} \mathrm{O}$ of G. ruber and (b) radiocarbon measurements on $G$. ruber converted to calendar age in ML1208-31BB. Shaded in grey is the interval at the core top showing a trend in both $\delta{ }^{18} \mathrm{O}$ and radiocarbon toward "older" values. value. For core $31 \mathrm{BB}$, we use the minimum ${ }^{14} \mathrm{C}$ age found at $12 \mathrm{~cm}$ (the depth of the $\delta^{18} \mathrm{O}$ minimum) as the uppermost age control point and do not use the ${ }^{14} \mathrm{C}$ or $\delta^{18} \mathrm{O}$ data above $12 \mathrm{~cm}$. For the other cores that show a core top $\delta^{18} \mathrm{O}$ reversal (10GC, 28BB, and 34BB), we again do not use the ${ }^{14} \mathrm{C}$ or $\delta^{18} \mathrm{O}$ data between the core top and the minimum $\delta^{18} \mathrm{O}$ and assign the age at the depth of the $\delta^{18} \mathrm{O}$ minimum to be the same as the age at the ${ }^{14} \mathrm{C}$ and $\delta^{18} \mathrm{O}$ minimum in 31BB.

The remaining age control points include the down-core radiocarbon dates where available (18GC and 31BB). Beyond the depth covered by the radiocarbon dates, and for the cores where no down-core radiocarbon dates were available, control points at the marine oxygen isotope stage boundaries were chosen and assigned ages from Lisiecki and Raymo [2005].

\subsubsection{Meridional $\delta^{18} \mathrm{O}$ Gradients} The G. ruber down-core $\delta^{18} \mathrm{O}$ records from the near-equatorial cores $\left(1^{\circ} \mathrm{S}\right.$ to $2^{\circ} \mathrm{N}$ ) show larger amplitudes (1.5\%o glacial-interglacial changes) than those in the North Equatorial Countercurrent (NECC) (1\%o glacial-interglacial changes). During warm periods the difference in the $\delta^{18} \mathrm{O}$ between the NECC and the near-equatorial core sites are smaller (0.27\%o during MIS 1 and $0.00 \%$ during MIS 5e). During cold periods, there are larger differences (0.45\%o during MIS 2 and $0.56 \%$ o during MIS 6 ) (Figure 10). The average values for each core for selected time slices (Table 1) are shown in Figure 11. For the cores where we have middle- to late-Holocene data $(0-6 \mathrm{ka})$, these data match well with the predicted $\delta^{18} \mathrm{O}$ for calcite precipitated in seawater with climatological annual average values. However, for the cores northward of $2^{\circ} \mathrm{N}$, we do not have any sediment core samples that are younger than $6 \mathrm{ka}$ in age. For the Early Holocene (6-10 kyr), the G. ruber $\delta^{18} \mathrm{O}$ at all latitudes matches well with the predicted values from climatology, once we account for the fact that the whole ocean $\delta^{18} \mathrm{O}$ was higher due to greater ice volume at this time. For the Last Glacial Maximum (19-23 kyr), the meridionial gradient exceeds that predicted from the modern climatological temperature and $\delta^{18} \mathrm{O}$ seawater values once we account for the whole ocean increase in $\delta^{18} \mathrm{O}$ due to the greater ice volume.

It is important to evaluate whether the changing latitudinal $\delta^{18} \mathrm{O}$ gradients of $G$. ruber could result from bioturbation or dissolution. Sedimentation rates in the NECC cores average about $1.5 \mathrm{~cm} \mathrm{kyr}^{-1}$, whereas they are higher (about $3 \mathrm{~cm} \mathrm{kyr}^{-1}$ ) closer to the equator (Table 1 and Figure 5). So we must consider the likelihood that the magnitude of glacial-interglacial change in the more northern cores may be more diminished by bioturbation than in the equatorial cores. However, even in the NECC we have cores with a variety of sedimentation rates, and the highest sedimentation rate core in the NECC (ML1208-31BB, MIS 1 to MIS 5 sedimentation rate of $3.2 \mathrm{~cm} \mathrm{kyr}^{-1}$ ) shows the same LGM oxygen isotope value as the lowest (ML1208-37BB, MIS 1 to MIS 5 sedimentation rate of $1.2 \mathrm{~cm} \mathrm{kyr}^{-1}$ ). We also consider the possibility that dissolution may lead to higher $\delta^{18} \mathrm{O}$ values in the Holocene sections of the more northern cores, creating an apparently diminished gradient relative to the LGM. Again, the consistency of the $\delta^{18} \mathrm{O}$ values between sediment cores of different water depths and sedimentation rates, as well as the consistency of the Holocene $\delta^{18} \mathrm{O}$ with 

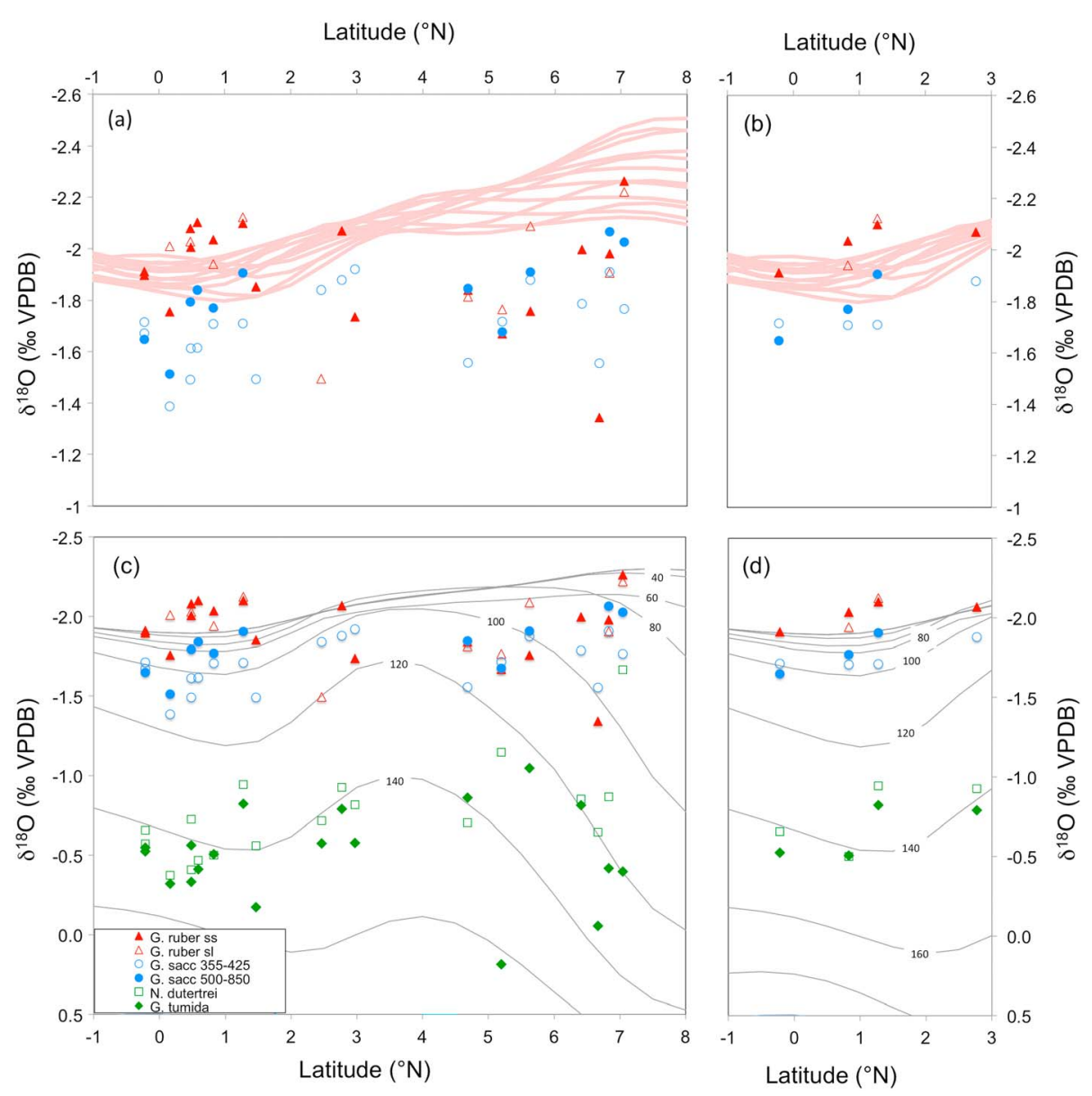

Figure 9. (a) Monthly average values of expected $\delta^{18} \mathrm{O}$ for calcite precipitated in surface waters (light red lines) along $160^{\circ}$ W. The red triangles are core top G. ruber $\delta^{18} \mathrm{O}$ (solid = sensu stricto, open = sensu lato) and blue circles are core top G. sacculifer (without sac) $\delta^{18} \mathrm{O}$ (solid $=500-850 \mu \mathrm{m}$ sieve fraction, open $=355-425 \mu \mathrm{m}$ sieve fraction). (b) Same as in (a), but only data from core tops that have a calendar age of $6 \mathrm{ka}$ or younger as determined by a core top radiocarbon date. (c) Annual average values of expected $\delta^{18} \mathrm{O}$ for calcite precipitated in subsurface waters (grey lines), and the $\delta^{18} \mathrm{O}$ of G. ruber, G. sacculifer, G. tumida, and N. dutertrei from core tops. (d) Same as in Figure 9a but only data from core tops that have a calendar age of $6 \mathrm{ka}$ or younger as determined by a core top radiocarbon date. Calcite $\delta^{18} \mathrm{O}$ is calculated using the relationship between $\delta^{18} \mathrm{O}$ of inorganic calcite and temperature of calcite precipitation [Kim and O'Neil, 1997], temperature, and salinity from the Monthly Isopycnal \& Mixed-layer Ocean Climatology [Schmidtko et al., 2013], and the surface and subsurface relationships between salinity and $\delta^{18} \mathrm{O}$ of seawater in this region from Conroy et al. [2014].

values predicted from climatological temperature and salinity, would argue against a strong effect. So the enhanced meridional gradient in $\delta^{18} \mathrm{O}$ of G. ruber likely reflects real oceanographic change, either greater equatorial cooling and/or an enhanced gradient in the $\delta^{18} \mathrm{O}$ of seawater $\left(\delta^{18} \mathrm{O}_{\mathrm{sw}}\right)$.

One possible cause of enhanced equatorial cooling would be that the equatorial cold tongue, which currently is more prominent farther to the east, was better developed at our site during glacial times. Today, the north-south temperature gradient is stronger in the eastern tropical Pacific than at our core site, reflecting a stronger contrast between the recently upwelled cold waters of the equatorial cold tongue and the warmer waters of the eastward flowing NECC. Shoaling of the thermocline during the LGM could have led to the upwelling of colder waters near the Line Islands leading to a stronger latitudinal temperature gradient. Some reconstructions and modeling studies do suggest a shallower thermocline in the Central Tropical Pacific during the LGM [Andreasen et al., 2001; Andreasen and Ravelo, 1997]. However, the LGM coupled model simulations suggest a thermocline deepening across the basin [DiNezio et al., 2011]. Changes in sea surface temperature patterns will ultimately reflect all changes in the surface heat budget, not simply upwelling from below. For example, a strengthening of the South Equatorial Current in response to a stronger Walker 


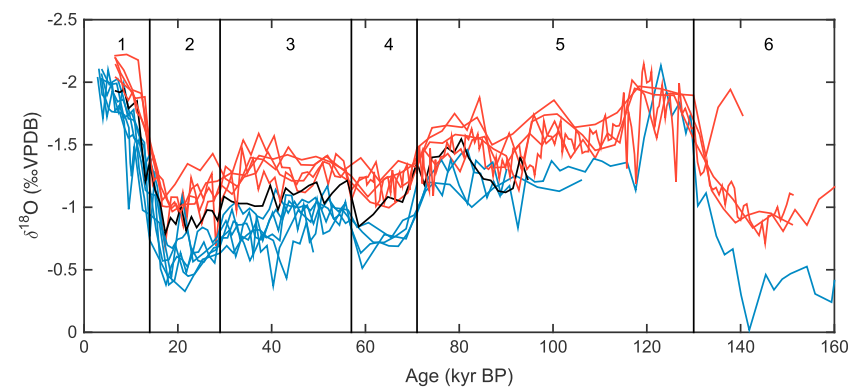

Figure 10. G. ruber $\delta^{18} \mathrm{O}$ values versus calendar age for all cores with down-core oxygen isotope data. Data from cores between the $1^{\circ} \mathrm{S}$ and $2^{\circ} \mathrm{N}$ (equatorial upwelling zone) are shown in blue, between 2 and $3.5^{\circ} \mathrm{N}$ in black, and 3.5 and $7^{\circ} \mathrm{N}$ (NECC) in red.

waters north of the equator are fresher and have lower $\delta^{18} \mathrm{O}_{\mathrm{sw}}$. The fresher waters in the NECC reflect both the addition of freshwater from rainfall under the central Pacific ITCZ, and the origin of these waters in the Western Pacific Warm Pool, which is also freshened by convective precipitation. Today, the freshest waters are in the western and eastern tropical Pacific, under the strong convective activity of the Western and Eastern Pacific Warm Pools, respectively (Figure 1). An increase in precipitation in the western or central tropical Pacific could have decreased the salinity and $\delta^{18} \mathrm{O}_{\mathrm{sw}}$ of the NECC, enhancing both the $\delta^{18} \mathrm{O}_{\mathrm{sw}}$ and the salinity gradient between the equatorial waters and the waters of the NECC. A decrease in western tropical Pacific salinity is inferred from sediment core data and is best simulated by models which show an increase in convection over the western Pacific compensating the decrease in convection over the exposed maritime continent in the Western Pacific Warm Pool [DiNezio and Tierney, 2013].

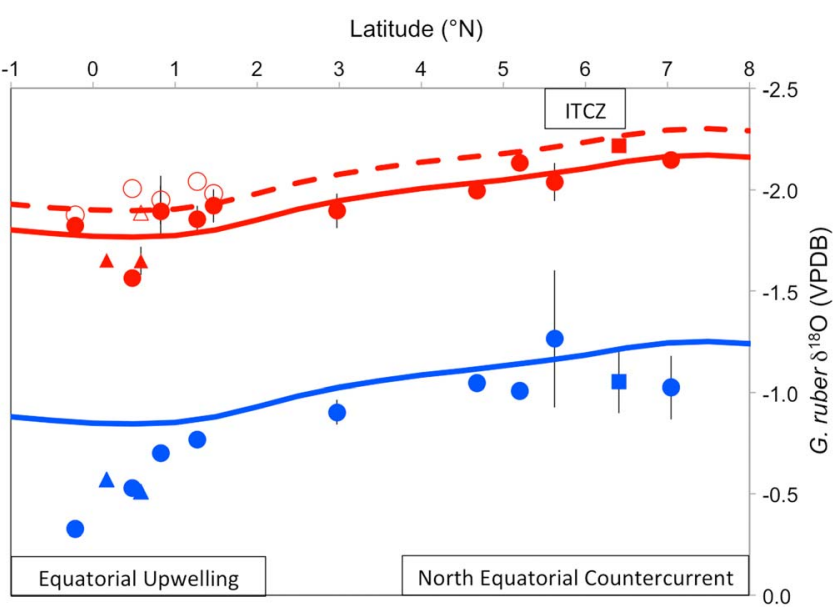

Figure 11. Average G. ruber $\delta^{18} \mathrm{O}$ for $0-6 \mathrm{ka}$ (open red symbols), 6-10 ka (closed red symbols), and 19-23 ka (closed blue symbols). Squares indicate data from cores above the saturation horizon $(2500 \mathrm{~m})$, circles indicate data from cores between 2700 and $3200 \mathrm{~m}$, and triangles data from cores deeper than $3200 \mathrm{~m}$. Error bars are 1 sigma standard deviation of the measurements within the time horizon (see Table 1). Also shown in the red dashed line is $\delta^{18} \mathrm{O}$ expected for calcite precipitated in surface waters (see Figure 9 caption). The red and blue solid lines are these values shifted by +0.13 and +1.05 , respectively, to reflect the increase in mean ocean $\delta^{18} \mathrm{O}$ due to larger amounts of land ice at 6-10 ka and 19-23 ka, respectively [Schrag et al., 2002; Siddall et al., 2009]. Within each time horizon, higher G. ruber $\delta^{18} \mathrm{O}$ indicates either colder temperatures ( $0.20 \%$ o for $1{ }^{\circ} \mathrm{C}$ cooling) or higher salinities $(0.31 \%$ o for 1 psu increase in salinity in this region today).
The magnitude of $\mathrm{LGM} \delta^{18} \mathrm{O}$ change in $\mathrm{G}$. ruber favors a change in NECC salinity as the more likely scenario. Numerous paleotemperature records from the eastern equatorial Pacific cold tongue, and east and west Pacific warm pools document 0 to 2.8 and 2 to $3.5^{\circ} \mathrm{C}$ of LGM cooling, respectively, based upon alkenone and $\mathrm{Mg} / \mathrm{Ca}$ paleothermometers (compiled in Ford et al. [2015]). If the central tropical Pacific experienced a similar amount of cooling as the warm pools, there should be a +0.4 to $+0.8 \%$ o positive shift in $\delta^{18} \mathrm{O}$ values of $G$. ruber beyond that from changes in $\delta^{18} \mathrm{O}_{s w}$ due to ice volume. The magnitude of LGM $\delta^{18} \mathrm{O}$ changes at the equatorial Line Island sites agrees with such a cooling while the off-equator sites are less positive than expected (Figure 11). If this magnitude of basin-wide cooling also applies to the northern Line Island sites, the observed changes in G. ruber $\delta^{18} \mathrm{O}$ require a more negative $\delta^{18} \mathrm{O}_{s w}$ in the NECC during the LGM. Independent paleotemperature estimates such as $\mathrm{Mg} / \mathrm{Ca}$ measurements in foraminifera will be critical to definitively distinguish 
between these scenarios, which have divergent implications for the state of the tropical Pacific climate during glacial times.

\section{Conclusions}

We have collected cores suitable for paleoceanographic research, with typical open ocean sedimentation rates and regionally coherent stratigraphies from the Line Island Ridge. At this location the seafloor morphology shows predominantly erosional features. This apparent contradiction reflects the fact that the erosion is episodic, and on time scales of tens to hundreds of thousands of years, sediment can accumulate undisturbed. We hope this encourages broad thinking about what locations are suitable for coring for paleoceanographic reconstructions. Despite the overall success in recovering suitable sediments, as at other locations at similar depths throughout the Pacific, the cores show old core top ages. This effect is particularly pronounced in the more northern cores with lower sedimentation rates, possibly reflecting processes such as recent dissolution and bioturbation. Oxygen isotope analyses on selected planktonic foraminifera species shows similar apparent calcification depths as has been found in other studies, with a surface calcification habitat for G. ruber. Down-core oxygen isotope measurements on G. ruber not only have helped to establish core stratigraphy but show that either the temperature or salinity gradient (or both) between the equator and $8^{\circ} \mathrm{N}$ was enhanced during cold climates. In conjunction with paleotemperature estimates, the data will be useful in determining how the Walker circulation changed during glacial and interglacial states and to what extent the precipitation patterns associated with the ITCZ may have changed.

\section{Acknowledgments}

The oxygen isotope, radiocarbon, and multisensor track data presented in this paper is archived at the World Data Center for Paleoclimatology operated by the National Climatic Data Center of the National Oceanographic and Atmospheric Association (data set ID: noaa-ocean-1001374). The multibeam data are archived at the National Geophysical Data Center (NGDC ID: NEW1888, Cruise ID: MGL1208). This work was supported by National Science Foundation grants OCE-1159053 and OCE-1003374 (J.L.-S.), OCE-1158886 (P.J. P.), and OCE-1157486 (M.L.), OCE-1158994 (R.P.). The authors would like to thank the Captain and crew of the R/V Marcus Langseth, the Oregon State University Coring group, the staff of the LDEO Marine Office, and the National Science Foundation for making the first coring cruise on the R/V Marcus Langseth a success. We thank Tiee-Yu Chang for laboratory assistance and the reviewers for their helpful comments.

\section{References}

Andreasen, D. H., A. C. Ravelo, and A. J. Broccoli (2001), Remote forcing at the Last Glacial Maximum in the tropical Pacific Ocean, J. Geophys. Res., 106, 879-897, doi:10.1029/1999JC000087.

Andreasen, D. J., and A. C. Ravelo (1997), Tropical Pacific Ocean thermocline depth reconstructions for the Last Glacial Maximum, Paleoceanography, 12, 395-413, doi:10.1029/97PA00822.

Bemis, B. E., H. J. Spero, J. Bijma, and D. W. Lea (1998), Reevaluation of the oxygen isotopic composition of planktonic foraminifera: Experimental results and revised paleotemperature equations, Paleoceanography, 13, 150-160, doi:10.1029/98PA00070.

Berelson, W. M., et al. (1997), Biogenic budgets of particle rain, benthic remineralization and sediment accumulation in the equatorial Pacific, Deep Sea Res., Part II, 44(9-10), 2251-2282.

Berger, W. H. (1973), Deep-Sea carbonates: Pleistocene dissolution cycles, J. Foraminiferal Res., 3, 187-195.

Berggren, W. A., D. V. Kent, and J. Van Couvering (1985), The Neogene: Part 2. Neogene chronology and chronostratigraphy, in The Geochronology and the Geologic Record, edited by N. J. Snelling, pp. 211-260, Geol. Soc., London.

Broecker, W., and E. Clark (2001), An evaluation of Lohmann's foraminifera weight dissolution index, Paleoceanography, 16, 531-534, doi:10.1029/2000PA000600.

Broecker, W. S., and E. Clark (1999), CaCO3 size distribution: A paleocarbonate ion proxy?, Paleoceanography, 14, 596-604, doi:10.1029/ 1999 PA900016.

Broecker, W. S., E. Clark, C. D. McCorkle, I. Hajdas, and G. Bonani (1999), Core top C-14 ages as a function of latitude and water depth on the Ontong-Java plateau, Paleoceanography, 14, 13-22, doi:10.1029/1998PA900009.

Conroy, J. L., K. M. Cobb, J. Lynch-Stieglitz, and P. J. Polissar (2014), Constraints on the salinity-oxygen isotope relationship in the central tropical Pacific Ocean, Marine Chem., 161C, 26-33, doi:10.1016/j.marchem.2014.02.001.

de Garidel-Thoron, T., Y. Rosenthal, L. Beaufort, E. Bard, C. Sonzogni, and A. C. Mix (2007), A multiproxy assessment of the western equatorial Pacific hydrography during the last 30 kyr, Paleoceanography, 22, PA3204, doi:10.1029/2006PA001269.

de Villiers, S. (2005), Foraminiferal shell-weight evidence for sedimentary calcite dissolution above the lysocline, Deep Sea Res., Part I, 52(5), $671-680$.

DiNezio, P. N., and J. E. Tierney (2013), The effect of sea level on glacial Indo-Pacific climate, Nat. Geosci., 6(6), 485-491.

DiNezio, P. N., A. C. Clement, G. A. Vecchi, B. J. Soden, and B. P. Kirtman (2009), Climate response of the equatorial Pacific to global warming, J. Clim., 22(18), 4873-4892.

DiNezio, P. N., A. Clement, G. A. Vecchi, B. Soden, A. J. Broccoli, B. L. Otto-Bliesner, and P. Braconnot (2011), The response of the Walker circulation to Last Glacial Maximum forcing: Implications for detection in proxies, Paleoceanography, 26, PA3217, doi:10.1029/ 2010 PA002083.

Dubois, N., M. Kienast, C. Normandeau, and T. D. Herbert (2009), Eastern equatorial Pacific cold tongue during the Last Glacial Maximum as seen from alkenone paleothermometry, Paleoceanography, 24, PA4207, doi:10.1029/2009PA001781.

Fairbanks, R., M. Sverdlove, R. Free, P. Wiebe, and A. Be (1982), Vertical distribution and isotopic fractionation of living planktonic foraminfera from the Panama Basin, Nature, 298, 841-844.

Farrell, J. W., and W. L. Prell (1991), Pacific Caco3 Preservation and Delta O-18 since 4 Ma: Paleoceanic and Paleoclimatic Implications, Paleoceanography, 6, 485-498, doi:10.1029/91PA00877.

Feldberg, M. J., and A. C. Mix (2002), Sea-surface temperature estimates in the Southeast Pacific based on planktonic foraminiferal species: Modern calibration and Last Glacial Maximum, Mar. Micropaleontol., 44(1-2), 1-29.

Ford, H. L., A. C. Ravelo, and P. J. Polissar (2015), Reduced El Nino-Southern Oscillation during the Last Glacial Maximum, Science, 347(6219), $255-258$.

Held, I. M., and B. J. Soden (2006), Robust responses of the hydrological cycle to global warming, J. Clim., 19(21), 5686-5699.

Kim, S. T., and J. R. O'Neil (1997), Equilibrium and nonequilibrium oxygen isotope effects in synthetic carbonates, Geochim. Cosmochim. Acta, 61(16), 3461-3475. 
Koutavas, A., and J. Lynch-Stieglitz (2003), Glacial-interglacial dynamics of the eastern equatorial Pacific cold tongue Intertropical Convergence Zone system reconstructed from oxygen isotope records, Paleoceanography, 18(4), 1089, doi:10.1029/2003PA000894.

Koutavas, A., J. Lynch-Stieglitz, T. M. Marchitto, and J. P. Sachs (2002), El Nino-like pattern in ice age tropical Pacific sea surface temperature Science, 297(5579), 226-230.

Lalicata, J. J., and D. W. Lea (2011), Pleistocene carbonate dissolution fluctuations in the eastern equatorial Pacific on glacial timescales: Evidence from ODP Hole 1241, Mar. Micropaleontol., 79(1-2), 41-51.

Lea, D. W., D. K. Pak, and H. J. Spero (2000), Climate impact of late quaternary equatorial Pacific sea surface temperature variations, Science, 289(5485), 1719-1724.

Leech, P. J., J. Lynch-Stieglitz, and R. Zhang (2013), Western Pacific thermocline structure and the Pacific marine Intertropical Convergence Zone during the Last Glacial Maximum, Earth Planet. Sci. Lett., 363, 133-143.

LeGrande, A. N., and G. A. Schmidt (2006), Global gridded data set of the oxygen isotopic composition in seawater, Geophys. Res. Lett., 33, L12604, doi:10.1029/2006GL026011.

Lisiecki, L. E., and M. E. Raymo (2005), A Pliocene-Pleistocene stack of 57 globally distributed benthic delta O-18 records, Paleoceanography, 20, PA1003, doi:10.1029/2004PA001071.

Liu, Z. Y., S. Vavrus, F. He, N. Wen, and Y. F. Zhong (2005), Rethinking tropical ocean response to global warming: The enhanced equatorial warming, J. Clim., 18(22), 4684-4700.

Locarnini, R. A., et al. (2013), World Ocean Atlas 2013, Temperature, vol. 1, edited by S. Levitus and A. Mishonov, 40 pp., NOAA Atlas NESDIS 73 Silver Spring, Md.

Lynch-Stieglitz, J., P. Polissar, and the scientific personnel of cruise MGL12-08 (2012), MGL12-08 Cruise Report: A summary of the objectives, methods, activities and findings from oceanographic research cruise MGL12-08 May 1-26, 2012 aboard the R/V Marcus G. Langseth.

Martinez, I., L. Keigwin, T. T. Barrows, Y. Yokoyama, and J. Southon (2003), La Nina-like conditions in the eastern equatorial Pacific and a stronger Choco jet in the northern Andes during the last glaciation, Paleoceanography, 18(2), 1033, doi:10.1029/2002PA000877.

Mix, A. C., A. E. Morey, N. G. Pisias, and S. W. Hostetler (1999), Foraminiferal faunal estimates of paleotemperature: Circumventing the noanalog problem yields cool ice age tropics, Paleoceanography, 14, 350-359, doi:10.1029/1999PA900012.

Pahnke, K., J. P. Sachs, L. Keigwin, A. Timmermann, and S. P. Xie (2007), Eastern tropical Pacific hydrologic changes during the past 27,000 years from D/H ratios in alkenones, Paleoceanography, 22, PA4214, doi:10.1029/2007PA001468.

Ravelo, A., and R. Fairbanks (1992), Oxygen isotopic composition of multiple species of planktonic foraminifera, Paleoceanography, 7 , 815-831, doi:10.1029/92PA02092.

Reimer, P. J., et al. (2013), Intcal13 and Marine13 radiocarbon age calibration curves 0-50,000 Years Cal Bp, Radiocarbon, 55(4), 1869-1887.

Rincon-Martinez, D., S. Steph, F. Lamy, A. Mix, and R. Tiedemann (2011), Tracking the equatorial front in the eastern equatorial Pacific Ocean by the isotopic and faunal composition of planktonic foraminifera, Mar. Micropaleontol., 79(1-2), 24-40.

Sadekov, A. Y., R. Ganeshram, L. Pichevin, R. Berdin, E. McClymont, H. Elderfield, and A. W. Tudhope (2013), Palaeoclimate reconstructions reveal a strong link between El Nino-Southern Oscillation and Tropical Pacific mean state, Nat. Commun., 4, 2692, doi:10.1038/ncomms3692.

Schmidtko, S., G. C. Johnson, and J. M. Lyman (2013), MIMOC: A global monthly isopycnal upper-ocean climatology with mixed layers, J. Geophys. Res. Oceans, 118, 1658-1672, doi:10.1002/jgrc.20122.

Schrag, D. P., J. F. Adkins, K. McIntyre, J. L. Alexander, D. A. Hodell, C. D. Charles, and J. F. McManus (2002), The oxygen isotopic composition of seawater during the Last Glacial Maximum, Quat. Sci. Rev., 21(1-3), 331-342.

Siddall, M., T. F. Stocker, and P. U. Clark (2009), Constraints on future sea-level rise from past sea-level change (Retracted article. See vol. 3, pg. 217, 2010), Nat. Geosci., 2(8), 571-575.

Spero, H. J., and D. W. Lea (1993), Intraspecific stable-isotope variability in the planktic foraminifera Globigerinoides-Sacculifer-Results from laboratory experiments, Mar. Micropaleontol., 22(3), 221-234.

Spero, H. J., K. M. Mielke, E. M. Kalve, D. W. Lea, and D. K. Pak (2003), Multispecies approach to reconstructing eastern equatorial Pacific thermocline hydrography during the past 360 kyr, Paleoceanography, 18(1), 1022, doi:10.1029/2002PA000814.

Steinke, S., H. Y. Chiu, P. S. Yu, C. C. Shen, L. Lowemark, H. S. Mii, and M. T. Chen (2005), Mg/Ca ratios of two Globigerinoides ruber (white) morphotypes: Implications for reconstructing past tropical/ subtropical surface water conditions, Geochem. Geophys. Geosyst., 6, Q11005, doi:10.1029/2005GC000926.

Steinke, S., M. Kienast, J. Groeneveld, L. C. Lin, M. T. Chen, and R. Rendle-Buhring (2008), Proxy dependence of the temporal pattern of deglacial warming in the tropical South China Sea: Toward resolving seasonality, Quat. Sci. Rev., 27(7-8), 688-700.

Thirumalai, K., J. N. Richey, T. M. Quinn, and R. Z. Poore (2014), Globigerinoides ruber morphotypes in the Gulf of Mexico: A test of null hypothesis, Sci. Rep., 4, doi:10.1038/srep06018.

Thompson, P. R., A. W. H. Be, J. C. Duplessy, and N. J. Shackleton (1979), Disappearance of pink-pigmented Globigerinoides-Ruber at 120,000-Yr $\mathrm{Bp}$ in the Indian and Pacific Oceans, Nature, 280(5723), 554-558.

Wang, L. J. (2000), Isotopic signals in two morphotypes of Globigerinoides ruber (white) from the South China Sea: Implications for monsoon climate change during the last glacial cycle, Palaeogeogr. Palaeoclimatol. Palaeoecol., 161(3-4), 381-394.

Watkins, J. M., A. C. Mix, and J. Wilson (1996), Living planktic foraminifera: Tracers of circulation and productivity regimes in the central equatorial Pacific, Deep Sea Res., Part II, 43(4-6), 1257-1282.

Watkins, J. M., A. C. Mix, and J. Wilson (1998), Living planktic foraminifera in the central tropical Pacific Ocean: Articulating the equatorial "cold tongue" during La Nina, 1992, Mar. Micropaleontol., 33(3-4), 157-174.

Zweng, M. M., et al. (2013), World Ocean Atlas 2013, Salinity, vol. 2, 39 pp., NOAA Atlas NESDIS 74, Silver Spring, Md. 